\title{
Bem-estar e pobreza: a abordagem de Sen em comparação à utilitarista e a dos bens primários
}

\author{
Cezar Augusto Pereira dos Santos* \\ Dieson Lenon Casagrande** \\ Paulo Henrique de Oliveira Hoeckel*** \\ Solange Regina Marin****
}

\begin{abstract}
Resumo: Este artigo aborda como objeto de estudo textos de Amartya Sen sobre BemEstar e Pobreza com o objetivo de contrapor os argumentos de Sen em relação a outras duas abordagens teóricas que tratam da mesma questão, a abordagem com base na utilidade e a abordagem Rawlsiana com foco nos bens primários, além de apresentar algumas abordagens que tratam da identificação e agregação dos indivíduos enquanto pobres. Os argumentos de Sen sustentam a hipótese assumida de que tanto em relação à questão do bem-estar quanto da pobreza, a abordagem dos funcionamentos e capacitações pode dar uma resposta mais consistente do ponto de vista moral, quando se leva em conta a diversidade humana, do que a abordagem utilitarista e a dos bens primários de Rawls.
\end{abstract}

Palavras-chave: Bem-Estar e pobreza; utilidade; capacitações.

Classificação JEL: I30; I31; I32;

\footnotetext{
*Professor na Universidade Comunitária da Região de Chapecó - UNOCHAPECÓ e na Universidade Regional Integrada - URI / FW. Mestre em Economia e Desenvolvimento (PPGE\&D/UFSM);

**Doutorando em Economia do PIMES/UFPE. Mestre em Economia e Desenvolvimento (PPGE\&D/UFSM);

***Doutorando em Economia do PPGE/PUCRS. Mestre em Economia e Desenvolvimento (PPGE\&D/UFSM);

****Professora adjunta do departamento de Ciências Econômicas da UFSM e do Programa de Pós-Graduação em Economia e Desenvolvimento (PPGE\&D/UFSM). Doutora em Desenvolvimento Econômico (UFPR)
} 


\section{Introdução}

O presente trabalho tem como objetivo analisar a visão de Amartya Sen em relação ao bem-estar em contraponto a outras duas abordagens teóricas que tratam da mesma questão - a abordagem com base na utilidade e a abordagem com foco nos bens primários. Além disso, busca-se também apresentar algumas abordagens que tratam da identificação e agregação dos indivíduos enquanto pobres, tomando como referencial teórico textos de Amartya Sen.

Sen realiza em seus estudos uma sólida crítica tanto às duas alternativas de tratamento da questão do bem-estar - sem deixar de reconhecer as contribuições que tanto uma quanto a outra proporcionaram ao avanço do estudo na área -, quanto às diferentes conceituações de pobreza e adicionalmente apresenta a sua própria abordagem do que vem a ser bem-estar e de como identificar e agregar a pobreza.

O problema que norteia o presente trabalho é o seguinte: Sen é capaz de apresentar uma alternativa de análise do bem-estar e pobreza sustentável do ponto de vista teórico quando em comparação com a abordagem com foco na utilidade?

Para testar a hipótese assumida de que a abordagem seniana tanto do bem-estar quanto da pobreza é mais rica e factível do que a tradicionalmente aceita, recorre-se neste trabalho a uma pesquisa bibliográfica tendo como referência livros e artigos escritos por Sen.

Além desta introdução, o presente trabalho conta com mais três seções. $\mathrm{Na}$ segunda é apresentada tanto a abordagem Utilitarista quanto Rawlsiana acerca do bem-estar e as críticas de Sen a cada uma delas, além da apresentação da abordagem do bem-estar com base nas capacitações e funcionamentos e sua defesa como uma perspectiva mais adequada. Na terceira seção, são analisadas, pela óptica de Sen, resumidamente algumas das diferentes abordagens que conceituam a pobreza e como elas identificam e agregam os indivíduos enquanto pobres. As considerações finais são feitas na quarta seção.

\section{Diferentes teorias acerca do bem-estar}

\subsection{A teoria do bem-estar com base na utilidade}

O utilitarismo, visto como uma teoria do bem-estar social ao mesmo tempo em que é uma abordagem amplamente utilizada ao longo do tempo nas análises de economistas que se debruçaram sobre questões como pobreza, desigualdade e desenvolvimento econômico, também sofre uma grande variedade de críticas.

Um dos grandes pressupostos utilitaristas é que a lógica por trás do comportamento do consumidor individual ${ }^{1}$ frente suas preferências, as

\footnotetext{
$1 \mathrm{Na}$ visão utilitarista o princípio da escolha racional de um único ser humano é estendido a escolha "racional" de toda uma sociedade. Ou seja, o princípio adequado para um único sujeito - racional - pode ser aplicado para toda a coletividade. Em tal concepção de sociedade os sujeitos separados são tomados como um certo número de curvas ao
} 
quais são consideradas transitivas ${ }^{2}$, pode ser estendida para uma função de preferência social, que nada mais seria do que a soma das utilidades individuais dos diferentes sujeitos. E que isto, por sua vez, geraria um resultado numérico capaz de refletir a utilidade total de uma sociedade. Assim, dada duas alocações hipotéticas, a alocação X e a alocação Y. A primeira alternativa seria preferível a segunda, caso o somatório das utilidades individuais dada a escolha da alocação $\mathrm{X}$ gerasse um resultado numérico maior do que aquele obtido pelo mesmo modo ao ser escolhida a alocação Y. Logo, tal função de bem-estar utilitarista (também conhecida como função de bem-estar de Bentham) proporcionaria a maximização da utilidade total e através de tal expediente faria com que fosse alcançada a alocação eficiente do ponto de vista social - ótimo no sentido de Pareto (Varian, 2006).

Conforme Sen e Williams (1983), as avaliações com base no utilitarismo combinam o consequencialismo, o welfarismo e o ranking pela soma. Para tais autores, o welfarismo restringe os juízos sobre os estados de coisas a uma função das utilidades obtidas nesse estado. Assim, por tal artifício, o conjunto de diversas informações sobre $n$ indivíduos em um estado se reduz a $n$ parcelas de utilidade com a totalidade de informações relevantes sendo dadas por um vetor $n$ de utilidades. Já o chamado ranking pela soma requer que as utilidades dos diferentes indivíduos sejam somadas em conjunto.

O consequencialismo, pressuposto utilitarista mais necessário à análise acerca do bem-estar e pobreza aqui feita, é a doutrina que afirma que as coisas devem ser julgadas moralmente tanto por seu valor intrínseco quanto pelo valor de suas conseqüências. Em um quadro consequencialista é necessário primeiro decidir o que é intrinsecamente valioso. Em particular, um consequencialista toma uma ação, política ou instituição como sendo moralmente correta ou direita ou permitida se os seus resultados não são piores no conjunto do que os resultados de qualquer alternativa isolada (Hausman e Mcpherson, 2006).

Conforme Sen (1979), a influência generalizada dos princípios utilitaristas deriva da "atratividade" daquilo que Thomas Scanlon chamou de "utilitarismo filosófico" - tese de que o único e fundamental fato moral é o que está por trás da busca pelo bem-estar individual [well-being]. O grande problema, segundo Sen (1985), é que existem diferentes visões utilitaristas acerca do que pode ser visto como bem-estar. Por exemplo, os grandes utilitaristas do século XIX (Bentham, Mill e Sidgwick) assumiam o bem-estar como reflexo da utilidade sobre um estado mental como felicidade ou prazer (ou mais precisamente como aquela propriedade dos objetos que causa tal estado mental). Por outro lado, os utilitaristas mais contemporâneos tomam o bem-estar como sendo a satisfação das preferências com base em um comportamento racional e auto-interessado (Hausman e Mcpherson, 2006).

Assim, é possível resumir o arcabouço teórico por trás da Economia do

longo das quais são alocados os escassos recursos de modo a tornar possível a máxima satisfação de desejos (RAWLS, 2008)

$2 \mathrm{O}$ pressuposto da transitividade afirma que se uma cesta x é preferível a uma cesta y, e que esta mesma cesta y é preferível à cesta $\mathrm{z}$, a cesta $\mathrm{x}$ deve ser necessariamente preferível à cesta $\mathrm{z}$. Isto ocorre, porque ao afirmar que uma cesta é preferível à outra, aquela gera uma utilidade maior que esta. Dessa forma, de acordo com o exemplo, seria impossível que a cesta z gerasse uma utilidade maior que a proporcionada pela cesta $\mathrm{x}$ (PINDICK e RUBINFELD, 2002). 
Bem-Estar por meio dos seguintes itens: os economistas devem concentrar suas avaliações sobre o bem-estar [well-being]; o método de avaliação utilizado deve ser o método de estimação (cálculo); o que interessa são as consequências das escolhas e atos para os indivíduos; o bem-estar é visto como a satisfação de preferências e apartir disso, o bem-estar é ostentado na avaliação com base nos resultados obtidos via mercado e conceito de ótimo paretiano ${ }^{3}$; além disso, outras noções éticas não vinculadas a satisfação de preferências, embora importantes, não são do interesse dos economistas (Hausman e Mcpherson, 2006 ).

\subsubsection{A crítica de Sen à abordagem utilitarista do bem-estar}

Conforme Sen (1979), embora o objetivo utilitarista seja maximizar a soma total da utilidade independentemente de como se dê a sua distribuição, ao mesmo tempo exige a igualdade da utilidade marginal de todos os indivíduos - utilidade marginal sendo vista como a utilidade incremental que cada pessoa iria receber de uma unidade adicional de um dado bem. De acordo com tal interpretação, essa igualdade de utilidades marginais engloba a igualdade de tratamento dos interesses de todos. O utilitarista John Harsanyi (1955), por exemplo, alega que uma habilidade exclusiva do utilitarismo é a de evitar a “discriminação injusta" entre "uma pessoa e outra". Em resposta, Sen (1979) argumenta que mesmo quando a utilidade é a única base de importância ainda assim existe a questão de saber se o tamanho da utilidade marginal, independentemente da utilidade total, apreciada pelos diferentes sujeitos, é um índice adequado da importância moral.

No caso dos seres humanos serem idênticos [e poderem ser agrupados dentro de uma função utilidade social], a aplicação do princípio prévio da universalizabilidade, sob a forma de "dar um peso igual ao interesse igual de todas as partes" simplificaria enormemente as análises sociais, já que a igualdade de utilidades marginais de todos coincidiria com igualdade de utilidades totais. Assim, uma análise interpretativa serviria igualmente bem para entender o comportamento tanto em relação a um sujeito quanto à coletividade (Sen, 1979).

O problema, segundo Sen (1979), é que tal visão deixa de levar em conta a diversidade individual, detendo-se exclusivamente no problema de como maximizar a utilidade total da sociedade. De modo a explicitar melhor sua crítica, o autor dá o seguinte exemplo: se uma pessoa A com deficiência física consegue obter metade da utilidade que uma pessoa B sem tal deficiência quando recebem ambas um mesmo nível de renda, então no problema de distribuição pura de renda entre A e B o utilitarista acabaria dando a pessoa B mais renda do que o pessoa A [o que faria com que a utilidade total aumentasse].

Assim, algumas questões devem ser analisadas. Primeiro, o utilitarismo não leva em conta quem tem menor utilidade total (por exemplo, o deficiente)

\footnotetext{
3 O chamado "Ótimo de Pareto" significa uma situação em que em um estado social qualquer se torna impossível aumentar a utilidade proporcionada a um indivíduo sem que isto necessariamente gere uma piora na utilidade proporcionada a outro indivíduo. Conforme Sen (1999) este critério foi o único a possibilitar comparações interpessoais de utilidade que "sobreviveu" quando as comparações interpessoais passaram a ser evitadas na Economia do bemestar.
} 
e que em qualquer nível de renda deve necessariamente ter também utilidade marginal inferior. Além disso, mesmo que o deficiente não estivesse em pior situação em termos de utilidade total, o mesmo poderia converter a renda em utilidade de forma menos eficiente. Então, mesmo que o utilitarista concedesse a mesma renda para A e B isto não seria "eficiente do ponto de vista econômico 4 " (Sen, 1979).

Em segundo lugar, conforme Sen (1985), se faz necessária uma base informacional mais rica do que a tradicional informação com base no bemestar individual - WAIF (Well-being As Informational Foundamentation). A questão para ele não é se o bem-estar é uma variável importante para uma análise intrinsecamente moral, mas se ela é a única base informacional a ser considerada [monismo informacional]. As pessoas têm outros objetivos além apenas do bem-estar individual [well-being] e nem todas as suas atividades visam à "maximização" do próprio bem-estar.

Sen argumenta que a concepção das "pessoas" na análise moral não pode ser tão reduzida a ponto de não dar nenhuma importância intrínseca a seu papel de agência, vendo-as, em última análise, apenas em termos de seu bem-estar individual [well-being]. Mas, mesmo enfatizando a limitação da WAIF como base informacional, na medida em que não dá lugar fundamental ao aspecto agência de uma pessoa, Sen não desconhece a importante relação que existe entre os aspectos de agência e o bem-estar de um indivíduo. Além disso, na visão de Sen, existe um sério problema com a abordagem utilitarista que resulta do fato de que o comportamento de escolha de um indivíduo pode não ter qualquer representação binária, ou pode ser representável por uma função binária que não seja transitiva. Por outro lado, conforme Sen, mesmo que a utilidade relacionada ao bem-estar individual [well-being] seja representada ao invés da renda pela felicidade ou pela satisfação de desejos, ainda assim, tal base informacional não é a mais recomendada (Sen, 1985).

Primeiro, porque tal como interpretada na tradição utilitarista, a felicidade é basicamente um estado mental, e ignora outros aspectos acerca do bem-estar de uma pessoa. Sen (1985) ilustra sua crítica a tal ponto de vista com o exemplo de um náufrago, que embora possa estar fustigado pela fome e pela doença, mas que através de algum condicionamento mental não se sinta infeliz com sua situação pode ser considerado, com base nessa perspectiva de felicidade, como "estando bem" (visão esta que na perspectiva de Sen seria um absurdo). Segundo, como um conceito de estado mental, a perspectiva da felicidade pode propiciar uma visão muito limitada de outras atividades mentais. Há estados mentais, além do estar feliz, como excitação, estimulação, etc, que são de relevância direta para o bem-estar [well-being] de uma pessoa, os quais diferem conforme as diferentes situações. Além disso, as atividades mentais envolvem a avaliação da vida - um exercício reflexivo - e o papel desta avaliação na identificação do bem-estar [well-being] da pessoa obviamente não pode ser visto apenas em termos de sua própria felicidade. Assim, para Sen, embora a felicidade seja de relevância evidente e direta para o bem-estar, ela é

4 A eficiência econômica também muitas vezes é denominada como "ótimo de Pareto", já que concerne exclusivamente à eficiência no espaço das utilidades não se atendo as considerações distributivas relativas à utilidade (SEN, 1999). 
inadequada como representação do bem-estar [well-being] (Sen, 1985).

Quanto a questão da utilidade sendo interpretada como a satisfação dos desejos, para Sen, a métrica necessária para uma informação adequada da visão de utilidade não pode ser obtida a partir da observação dos objetos de desejo. A força dos desejos teriam que entrar em cena e os desejos de diferentes sujeitos teriam de ser comparados. Para Sen (1985), comparações de intensidades de desejos poderiam ser, na verdade, um guia muito duvidoso para comparar intensidades de bem-estar de uma pessoa com outra, uma vez que essas intensidades são influenciadas por muitas circunstâncias contingentes que são arbitrárias. A leitura do que é possível a cada pessoa obter nas diferentes situações em que se encontra pode ser crucial para a intensidade de seus desejos e pode afetar até mesmo o que ele ousa desejar.

"Os destituídos que têm apenas o desejo desesperado de
sobreviver, o trabalhador sem-terra que concentra seus esforços
em garantir a próxima refeição, a dona de casa oprimida que luta
por um pouco de individualidade, podem todos ter aprendido a
manter seus desejos de acordo com as suas respectivas situações
difíceis. Suas privações ficam amordaçadas e abafadas na
métrica interpessoal de realização de desejos. Em algumas vidas
pequenas misericórdias tem um valor muito grande" (Sen, 1985, pp. 191).

Logo, tendo como referência os diferentes estudos de Sen, fica claro que a base informacional do bem-estar gerado pela WAIF deixa em aberto a forma como combinar o bem-estar das diferentes pessoas de forma a avaliar os estados e ações. Sem falar que torna possível perceber que o utilitarismo passa ao largo do problema relacionado à questão da desigualdade de oportunidades disponíveis as pessoas.

\subsection{A teoria do bem-estar de Rawls com base nos chamados bens primários}

Em seu livro "Uma teoria da justiça", Rawls (2008) se intitula um teórico defensor do contrato social tal como Locke, Rousseau e Kant e que os princípios de justiça que norteiam a estrutura básica de sua visão de sociedade constituem o objeto do acordo original. Tais princípios, segundo Rawls, são os das pessoas livres e racionais, interessadas em promover seus próprios interesses, que os aceitariam em uma situação inicial de igualdade como definidores das condições fundamentais de sua associação - "posição original".

Conforme Hausman e Mcpherson (2006), na obra "Uma teoria da justiça", Rawls analisa o bem estar individual como sendo a satisfação das preferências racionais. Porém, ele não pensa que o foco da justiça deva se dar com base no bem estar individual do ponto de vista da satisfação de utilidades e sugere que o aspecto relevante do bem estar individual seja medido por um índice de bens 
primários sociais - que seja capaz de proporcionar a equidade entre os diferentes sujeitos. Rawls (2008) na verdade define tal índice como um agregado de bens primários que um indivíduo representativo deseja, não importando o que mais ele deseje e tais bens primários sociais englobam tanto categorias amplas como direitos, liberdades e oportunidades, quanto a renda.

$\mathrm{Na}$ teoria da justiça como equidade, Rawls apresenta os dois princípios básicos:

\begin{abstract}
"Primeiro: cada pessoa deve ter um direito igual ao sistema mais extenso de iguais liberdades fundamentais que seja compatível com um sistema similar de liberdades para as outras pessoas. Segundo: as desigualdades sociais e econômicas devem estar dispostas de tal modo que tanto (a) se possa razoavelmente esperar que se estabeleçam em benefício de todos como (b) estejam vinculadas a cargos e posições acessíveis a todos" (Rawls, 2008, pp. 73).
\end{abstract}

Sen (1979), ao analisar os dois princípios de Rawls, aponta para o fato de que as liberdades básicas são separadas como tendo prioridade sobre outros bens primários e, portanto, a prioridade é dada ao princípio da liberdade, que exige que "cada pessoa deve ter um direito igual à mais extensa liberdade básica compatível com uma liberdade similar para os outros.” Já o segundo princípio suplementa este, exigindo eficiência e igualdade.

$\mathrm{Na}$ sua visão de bem-estar, Rawls (2008) não se limita a um único princípio geral, como a utilidade, pois leva em conta os bens primários desde a renda até a liberdade. Além disso, o indivíduo Rawlsiano embora tenha algum projeto de vida racional não conhece os pormenores desse projeto, todos os seus objetivos e os interesses específicos que tem como objetivo promover. Ou seja, tal indivíduo está muito mais para o conceito de razoabilidade do que para o conceito de fria racionalidade munida de informações perfeitas tal como apregoado pelo utilitarismo. Outra questão chave na obra de Rawls é que as desigualdades são condenadas a menos que levem ao benefício coletivo. Tal autor apresenta o chamado "princípio da diferença" [ou critério maximin ${ }^{\text {] }}$ de justiça social através do qual é dada prioridade para a promoção dos interesses daqueles sujeitos em pior situação dentro da coletividade (Rawls, 2008).

\title{
2.2.1 A crítica de Sen sobre a abordagem do bem-estar com base nos bens primários
}

Embora Sen (2009) não concorde com a ideia de imparcialidade capturada no dispositivo reflexivo da "posição original" de Rawls, ele não discorda de sua ideia básica de priorizar a equidade (cujo conceito é diferente do de igualdade), assim como da visão acerca dos indivíduos indo além apenas

5 Abreviação de maximum minimorum. Rawls utiliza tal termo para designar a regra de decisão segundo a qual os agentes racionais, sob condições de incerteza, optam pela alternativa cujo pior resultado possível ainda assim é melhor do que os piores resultados das demais alternativas levadas em conta (RAWLS, 2008). 
do seu auto-interesse. Sen vê como positivo o fato de Rawls, na primeira parte de seu segundo princípio, insistir na necessidade de equidade processual, já que boa parte da literatura em relação à desigualdade no campo das ciências sociais tende a se concentrar exclusivamente nas disparidades de status sociais ou resultados econômicos (como será aprofundado na seção que abordará a questão da pobreza). Sen também entende como importante a contribuição de Rawls ao tornar explicita a importância da necessidade da equidade em arranjos sociais para que se preste atenção nas dificuldades pelas quais passam as pessoas em pior situação [embora Sen não concorde que o foco deva ser mantido única e exclusivamente sobre a privação relacionada aos bens primários] (Sen, 2009).

Além disso, conforme Sen, como o princípio da diferença é equitativo, Rawls evita o recurso de ter de dar mais renda para as pessoas que possuem gostos caros. Assim, uma vez que vantagem é julgada não em termos de utilidade em tudo, mas por meio do índice de bens primários, gostos caros deixarão de fornecer um terreno para se obter mais renda. Porém, por outro lado, Sen deixa claro que o fato do segundo princípio de Rawls suplantar o primeiro vem a ter sérias conseqüências sobre o exemplo do deficiente físico antes abordado (Sen, 1979).

Sen, como visto acima, afirma que em um problema de distribuição, um utilitarista daria menos renda ao indivíduo deficiente e mais a outro sujeito capaz de obter maior utilidade com a renda. Já no caso do princípio da diferença, segundo Sen, o deficiente não receberá nem mais nem menos, por causa de sua deficiência. A justificativa para isso, conforme Rawls, é que tais casos como o do deficiente se enquadram naquilo que ele chama de "casos difíceis», os quais podem «distrair a nossa percepção moral, levando-nos a pensar em pessoas distantes de nós cujo destino desperta piedade e ansiedade.» A resposta de Sen a tal argumento de Rawls é que tais casos "difíceis" existem, e que tomar as deficiências ou necessidades especiais de saúde, ou defeitos físicos ou mentais, como moralmente irrelevantes, ou deixá-las de fora por medo de cometer um erro, pode garantir o oposto (Sen, 1979).

Outra crítica de Sen sobre a abordagem dos bens primários de Rawls é que o julgar as oportunidades que as pessoas têm por meio dos meios que estas possuem e acaba não levando em conta as amplas variações quanto às capacidades de converter os bens primários em viver bem. Por exemplo, o deficiente do exemplo pode, tudo o mais permanecendo constante, fazer muito menos com a mesma quantidade de renda que uma pessoa sem tal deficiência (Sen, 2009).

Ao analisar a abordagem de Rawls, Sen afirma que caso as pessoas fossem basicamente muito semelhantes, então um índice de bens primários poderia ser um bom caminho para julgar as vantagens. Mas, na verdade, as pessoas parecem ter necessidades muito diferentes, variando com a saúde, a longevidade, condições climáticas, localização, temperamento, e até mesmo com o tamanho do corpo - que afeta as necessidades alimentares e de vestuário (Sen, 1979).

Logo, para Sen, o que está envolvido não é simplesmente o fato de se 
ignorar alguns casos difíceis, mas questões muito mais amplas e reais. Pois, o julgamento das vantagens com base apenas em termos de bens primários levaria a uma análise parcialmente cega do ponto de vista moral.

\subsection{A teoria do bem-estar com base nas capacitações e funcionamentos}

Conforme Sen (1979), o que falta tanto à abordagem do bem-estar levando em conta a utilidade, quanto a do bem-estar com base nos bens primários é dar a devida relevância à diversidade humana e as diferentes capacitações individuais. Tais capacitações englobam não só a capacidade de satisfazer nossas necessidades nutricionais, os meios para se vestir e proteger, mas até mesmo o poder de participar da vida social da comunidade. E, tal noção não é totalmente captada por qualquer abordagem que dê primazia a utilidade ou aos bens primários, ou a qualquer combinação entre estas duas abordagens.

Para Sen (1979), a abordagem dos bens primários apresenta uma deficiência fetichista ao se preocupar com os bens, e mesmo que a lista de bens seja especificada de forma ampla e abrangente, englobando direitos, liberdades, oportunidades, renda, riqueza, e as bases sociais do auto-respeito, ainda assim está preocupada com boas coisas, e não com o que essas boas coisas podem fazer pelos seres humanos. Já a utilidade, por outro lado, está preocupada com o que essas coisas podem gerar para os seres humanos, mas usa uma métrica que não foca nas capacitações das pessoas, mas em sua reação mental. Ou seja, para Sen, ainda falta algo, e este algo é primordial. Logo, o foco dos estudos de Sen pode ser visto como uma extensão da preocupação de Rawls com bens primários, porém desviando a atenção dos bens para o que os bens podem fazer pelos seres humanos, da renda para aquilo que se faz da renda e assim por diante (Sen, 1979).

Antes de apresentar a abordagem do bem-estar com base nas capacitações é útil analisar a distinção feita por Sen acerca de duas ideias que embora intimamente relacionadas, são claramente diferentes. Uma delas é a idéia de estar "bem de vida" (ou abastado) [well-off] e a outra a de estar "bem" [well] ou de se apresentar como tendo "bem-estar" [well-being]. O primeiro é realmente um conceito de opulência - o quão rica é uma pessoa? que bens e serviços que ela pode comprar? quais ofícios e profissões estão abertos a ela? e assim por diante. Isto se refere ao "comando" de uma pessoa sobre as coisas externas a ela - incluindo aquilo que Rawls chamou de "Bens Primários". O segundo conceito, "bem-estar", por outro lado, não é algo externo ao indivíduo ou algo que ele comanda, mas algo que ele alcança. Que tipo de vida ele está levando? O que ele consegue fazer e ser? Assim, estar "bem de vida" [well-off] pode ajudar, dadas outras coisas, a se ter "bem-estar" [well-being], mas, existe uma qualidade distintamente pessoal no último conceito que se faz ausente no primeiro (Sen, 1985).

Para Sen, a principal característica do bem-estar pode ser vista em termos de como uma pessoa pode "funcionar", tomando esse termo em um 
sentido bastante amplo, o que engloba diversos "fazeres", como por exemplo, atividades como comer, ler, ver, andar, ou "ser - estar", como por exemplo, estar bem nutrido, livre da malária, não ter vergonha pela pobreza da roupa que veste e por aí afora (Sen, 1985).

$\mathrm{Na}$ análise de Sen em relação ao bem-estar, fica clara a importância de ser capaz de discernir o contraste entre bem-estar e opulência (representada pela renda). Sen afirma que o exemplo do deficiente físico (ou de maneira semelhante qualquer outra limitação pessoal) pode, em alguns aspectos, ser particularmente enganoso, ao sugerir que as diversidades pessoais são coisas incomuns e inusitadas. Na verdade, segundo ele, as variações interpessoais em "transformar" bens em funcionamentos são extremamente comuns. Como exemplo disto, cita o caso do consumo de alimentos, por um lado, e o funcionamento de estar bem nutrido, por outro. A relação entre estes varia de acordo com (1) as taxas metabólicas, (2) tamanho do corpo, (3) idade, (4) sexo (e se uma mulher está grávida ou amamentando), (5) os níveis de atividade, (6) as condições climáticas (7), presença de doenças parasitárias, (8) o acesso a serviços médicos, (9) o conhecimento acerca de nutrição, e outras influências (Sen, 1985).

Mas, conforme Sen, as diferenças interpessoais não são, naturalmente, limitadas a tais funcionamentos elementares como estar bem nutrido, ou escapar da morbidade evitável. Influências pessoais e sociais sobre a conversão da opulência em realizações de funcionamentos podem ser importantes em muitos outros campos. As necessidades de recursos de funcionamentos como "aparecer em público sem sentir vergonha" (enfatizada por Adam Smith), participar da vida da comunidade, ser capaz de visitar e receber amigos, estar razoavelmente bem informado, e assim por diante, variam conforme as características (culturais, sociais, religiosas...) da comunidade em que se vive. Desse modo, para Sen, o pluralismo das informações acerca do bem-estar presente na abordagem dos funcionamentos tem de ir além, e desviar a atenção dos funcionamentos reais do sujeito para as suas capacitações para funcionar. Assim, o conjunto capacitário de um agente (e o termo agente é central na abordagem do bem-estar tendo como base as capacitações) pode ser definido como um conjunto de vetores de funcionamentos que estão ao seu alcance. Ao examinar o aspecto do bem-estar de um agente, a atenção pode e deve legitimamente ser desviada para o seu conjunto capacitário e não apenas para o seu vetor de funcionamentos escolhido (Sen, 1985).

Segundo Sen, com relação as oportunidades reais, a vantagem de um indivíduo será considerada menor quando em comparação a de outro, se aquele tem menor capacitação (no sentido de menos oportunidades reais) para realizar as coisas que valoriza quando em comparação a este. Por exemplo, Sen afirma que uma pessoa pode ao mesmo tempo ter uma renda alta e um problema de saúde crônico que a impede de deixar um leito de hospital. Assim, tal indivíduo não pode ser visto como tendo uma grande vantagem em relação aos demais simplesmente por ter maior renda. Pois, ele possui mais de um funcionamento [renda] para viver bem, mas enfrenta dificuldades em converter tal vantagem 
[capacitação] em uma forma de vida que tenha razão para valorizar (SEN, 2009).

O foco da abordagem das capacitações é a liberdade que um agente tem para fazer ou ser algo que ele valoriza levando em conta a vida humana como um todo e não apenas a satisfação de um estado mental com base na utilidade ou o acesso a um conjunto de bens primários, os quais mesmo sendo importantes ainda assim são meios (renda, riqueza, prerrogativas associadas a cargos) para outra coisa - liberdade. Ou seja, há uma transferência de foco dos meios para as oportunidades, que com base na razão proporcionará aos "agentes" as condições de atingir os fins que "eles decidiram" alcançar (Sen, 2009).

Mas, para que os "agentes" sejam capazes de atingir os fins que valorizam se faz necessário que eles não sejam "pobres”. A próxima seção aborda resumidamente a complexidade por trás da conceituação da pobreza.

\section{Diferentes modos de identificar e conceituar a pobreza}

Conforme Sen (1981), o primeiro requisito para se chegar a um conceito de pobreza é ter um critério sobre a quem deveria ser direcionado o foco de análise [who]. Para Sen (2001), o problema de avaliação da pobreza, assim como da desigualdade, depende do espaço informacional onde tanto esta quanto aquela são analisadas. Além disso, a questão de quem é ou não pobre só é capaz de gerar uma resposta satisfatória caso o propósito e a motivação por trás do questionamento seja previamente especificado. $\mathrm{O}$ autor mostra ao longo de seus diferentes textos que a abordagem mais comum nos estudos que envolvem a Economia do bem-estar é a de considerar o vetor renda como uma "proxy" tanto para analisar os problemas que envolvem latentes desigualdades sociais, quanto para identificar quem pode ser considerado "pobre".

Conforme Sen (2001), a mensuração da pobreza pode ser vista como sendo constituída de dois exercícios distintos, porém inter-relacionados: (1) a "identificação" dos pobres, e (2) a "agregação" dos parâmetros estatísticos com respeito aos identificados como pobres para derivar um índice global de pobreza.

Em relação à identificação dos pobres, Sen (1981) afirma que a abordagem mais tradicional envolve a contagem do número de pobres, e depois a pobreza é expressa (agregação) como a razão entre o número de pobres e o número total de pessoas da comunidade em questão ${ }^{6}$. Mas, para Sen, tal medida de contagem per capita tem alguns inconvenientes bastante graves. Primeiro, ela não leva em conta o quão perto ou longe as pessoas consideradas como "pobres" podem estar da linha de pobreza estipulada - por exemplo, João pode estar vivendo com US $\$ 1,99$ por dia, ao passo que Pedro pode estar vivendo com US\$ 0,50 por dia. Além disso, a redução na renda de todos os indivíduos considerados pobres sem que isto afete negativamente a renda daqueles considerados ricos mantém inalterada esta medida de contagem per capta (o que viola o axioma da

6 Nesta abordagem, para se chegar ao número de indivíduos que incidem na classe dos chamados "pobres", a identificação é feita utilizando-se a renda relativa à linha de pobreza (a qual conforme a ONU é de menos US $\$ 2,00$ per capta por dia) como uma divisão. O método de agregação, neste sistema, consiste em encontrar o índice H - o qual é a contagem do número de indivíduos que vivem com renda abaixo desta linha de pobreza (SEN, 2001). 
monotonicidade). Sem falar que uma transferência de renda entre aqueles que já estão abaixo da linha da pobreza, embora deixe uma pessoa com mais renda e outra com menos renda, não levará a nenhuma alteração na medida de pobreza - o que por sua vez viola o axioma da transferência ${ }^{7}$ (Sen, 1981).

\subsection{A abordagem biológica da pobreza}

Sen analisou as diferentes abordagens acerca da identificação e agregação relacionadas ao conceito de pobreza que buscam se contrapor a abordagem utilitarista. A primeira dessas alternativas analisadas foi a da "abordagem biológica", que define famílias pobres como sendo aquelas que se encontram em um estado de "pobreza primária", cujos ganhos totais sejam insuficientes para obter o mínimo necessário para manter a sua capacidade de sobrevivência. Por este ponto de vista, a eficiência teria a ver com a mera satisfação de necessidades físicas elementares.

A crítica de Sen a esta abordagem é que, em primeiro lugar, existe uma significativa variação relacionada às características físicas, condições climáticas e hábitos de trabalho das diferentes pessoas que fazem com que a satisfação das necessidades físicas elementares apresente inúmeras nuances. Em segundo lugar, a tradução de um mínimo de exigências nutricionais para a satisfação das necessidades alimentares mínimas depende da escolha dos bens e a escolha dos bens está conectada também com fatores como preços dos alimentos e hábitos alimentares, que influenciam, por sua vez, o padrão de consumo dos indivíduos (Sen, 2001).

Embora Sen conteste o procedimento usado na abordagem biológica, ele defende que um aspecto desta abordagem deve ser mantido - o conceito de necessidades nutricionais satisfeitas como um dos elementos primordiais a serem levados em conta na conceituação da pobreza. Mas, para Sen, a verificação de se as pessoas estão tendo acesso ou não a um pacote específico de nutrientes, não precisa necessariamente passar pelo procedimento de examinar se essa pessoa tem o nível de renda capaz de propiciar a compra de tal pacote. Podese simplesmente analisar se a pessoa está de fato satisfazendo ou não suas necessidades nutricionais.

Conforme Sen (1981), mesmo em países pobres, informações nutricionais diretas desse tipo podem ser recolhidas de maneira relativamente fácil através de pesquisas por amostragem. A grande vantagem de tal abordagem, para Sen, é que o exercício da "identificação" da pobreza não precisa se dar por intermédio da renda e leva em conta a desnutrição, que é um aspecto particularmente importante para a análise da pobreza.

\footnotetext{
7 Enquanto o axioma da monotonicidade afirma que, tudo o mais permanecendo constante, uma redução na renda de uma pessoa que esteja abaixo da linha da pobreza deve fazer com que haja um aumento na medida utilizada para analisar a pobreza, o axioma da transferência parte do pressuposto de que tudo o mais permanecendo constante, uma transferência puramente de renda de uma pessoa que esteja abaixo da linha de pobreza para alquém que é seja mais rico deve levar a um incremento na medida de pobreza (SEN, 1976).
} 


\subsection{A abordagem da pobreza com foco na desigualdade de renda}

Outra abordagem analisada por Sen é a que trata a pobreza como sinônimo de desigualdade. Sen chama a atenção para a idéia de que o conceito de pobreza como sendo essencialmente o de desigualdade tem alguma plausibilidade imediata. Afinal de contas, segundo ele, as transferências dos ricos para os pobres pode fazer uma substancial diferença sobre a pobreza na maioria das sociedades. Porém, Sen esclarece que a desigualdade é, fundamentalmente, uma questão diferente da pobreza e que tentar analisar a pobreza "como uma questão de desigualdade", ou o contrário, acaba não fazendo justiça nem a um conceito nem ao outro (SEN, 1981).

Segundo Sen, um conceito não subordina o outro. Por exemplo, a transferência de renda de uma pessoa do grupo de renda "superior" para uma na faixa de renda "média" deve, tudo o mais constante, reduzir a desigualdade, mas isto pode viesar a percepção da pobreza. Da mesma forma, uma redução geral na renda que mantivesse a medida escolhida de desigualdade inalterada poderia, de fato, levar a um aumento acentuado nas dificuldades como fome e desnutrição. Assim, para Sen, nem a pobreza nem a desigualdade podem realmente ser subordinadas uma pela outra, embora seja evidente, como ele deixa claro, que uma questão completamente diferente é reconhecer que a desigualdade e a pobreza estão associadas, e que um sistema de distribuição mais equitativo pode atenuar sobremaneira a pobreza, mesmo sem uma expansão da capacidade produtiva do país. (Sen, 1981).

\subsection{A abordagem da pobreza com foco na privação relativa}

Sen (1981) analisou também a abordadem da pobreza que toma como foco a privação relativa. O conceito de "privação relativa", conforme Sen, foi frutiferamente utilizado na análise da pobreza, especialmente na literatura sociológica, já que é natural que, para um animal social [como o homem], o conceito de privação seja um conceito relativo. Porém, para Sen, dentro da uniformidade do termo "privação relativa", parece existir algumas noções distintas e diferentes. Assim, ele desagrega o conceito de privação em dois conceitos - os "sentimentos de privação" e as "condições de privação".

Segundo Sen, a "privação relativa" pode ser analisada em um sentido objetivo [condição objetiva] para descrever situações onde as pessoas possuem menos de algum atributo desejado, seja de renda, condições favoráveis de emprego, ou de poder em comparação as outras pessoas. Para Sen, as "condições de privação" não podem ser independentes dos "sentimentos de privação". Pois, neste contexto, os objetos materiais não podem ser avaliados sem que se leve em conta o modo como as pessoas os veem, e, segundo Sen, mesmo que os "sentimentos" não sejam explicitamente levados em conta na análise, eles devem ter um papel implícito por trás das escolhas - que não deve ser menosprezado (Sen, 1981). 
Uma outra questão importante relacionada a abordagem da pobreza, tendo como base a privação relativa, diz respeito à escolha de "grupos de referência" para comparação. Para Sen, o foco deve se ater aos grupos com os quais as pessoas em questão na verdade estão se comparando e isso pode ser um dos aspectos mais difíceis do estudo da pobreza com base em privação relativa. O horizonte de comparação não é, naturalmente, independente da atividade política na comunidade em questão, uma vez que a sensação de privação está intimamente relacionada às expectativas dos indivíduos em análise, bem como a sua visão do que é justo e do que os mesmos se acham no direito de desfrutar. Estas diferentes questões relacionadas com a noção geral de privação relativa, para Sen, tem influência considerável sobre a análise da pobreza social (Sen, 1981).

Sen afirma que é interessante notar que a abordagem de privação relativa - embora importante - não pode realmente ser a única base para o conceito de pobreza. A fome, por exemplo, será prontamente aceita como um caso de pobreza aguda, não importando qual o padrão relativo que possa existir dentro da sociedade. Na verdade, para o autor existe um núcleo irredutível de privação absoluta por trás da idéia de um diagnóstico de pobreza, o qual se traduz em relatos de desnutrição, fome e miséria, que é visível sem ter que se verificar primeiro uma imagem relativa. Assim, na visão de Sen, a abordagem de privação relativa suplementa, e não suplanta a análise da pobreza em termos de desapropriação absoluta (Sen, 1981).

\subsection{A abordagem Seniana da pobreza}

Sen (1981) levanta a seguinte questão: o conceito de pobreza está relacionado com os interesses de quem: (1) somente dos pobres, (2) somente dos não-pobres, ou (3) tanto dos pobres quanto dos não-pobres? O autor argumenta que embora a alternativa (3) possa parecer atraente, uma vez que é ampla e irrestrita (e que de fato há pouca dúvida de que a penúria dos pobres também afeta o bem-estar dos ricos), a verdadeira questão é saber se tais efeitos devem fazer parte de um conceito de pobreza, ou se devem ser entendidos como os possíveis efeitos da pobreza em si.

Conforme Sen (1981), a análise da pobreza não necessita ser independente da sociedade na qual esta está sendo avaliada e a privação não pode deixar de levar em conta o modo como os diferentes tipos de penúrias são vistos na sociedade em questão. Além disso, as diversidades entre sociedades não significam que muitos dos acordos sobre aquilo que é aceito como uma grave privação [como a subnutrição e a morbidade] se tornem inválidos. Ao contrário, Sen (2001) argumenta que certos funcionamentos gerais básicos e as capacitações a eles correspondentes, podem suscitar nuito mais acordo sobre sua importância do que ocorreria se a concentração se desse sobre pacotes particulares de mercadorias e meios particulares de realizar tais funcionamentos. Em apoio a tal ponto de vista, Sen exemplifica que, muito provavelmente, seria mais fácil 
um acordo intercultural [e interpessoal] sobre a importância dos agentes em deter a capacitação para evitar a fome aguda ou subnutrição severa do que sobre a importância de ter um suprimento de itens particulares de alimentação para ser capaz de exercer os funcionamentos (Sen, 2001).

Então, na óptica de Sen (2009), a pobreza é melhor conceituada e pode ser melhor enfrentada partindo do ponto de vista de que ela nada mais é do que a deficiência de capacitações ao invés de simplesmente uma deficiência em se satisfazer as "necessidades básicas" dos indivíduos via acesso a bens específicos. Ou seja, o campo de atuação deve ir além do espaço dos recursos e mercadorias e englobar o espaço da transformação destes recursos em funcionamentos proporcionando assim a aquisição de um rico conjunto capacitário a todos os agentes.

Sen argumenta $^{8}$ por fim, de maneira clara e conclusiva que se, hipoteticamente, ocorre uma redução da renda real e aumento do sofrimento de "todos" os pobres, tal caso deve ser descrito como um aumento da pobreza em si, e o fato de se esta mudança é acompanhada ou não por uma redução nos efeitos adversos sobre os indivíduos mais abastados da sociedade (por exemplo, se os ricos se sentem menos "ofendidos" pela visão de penúria) não é de grande relevância.

\section{Conclusões}

Neste trabalho foi possível perceber que, com base nos diferentes textos de Amartya Sen relacionados tanto à questão do bem-estar quanto da pobreza, faz-se necessária uma base informacional mais rica do que o tradicional monismo informacional da WAIF . Além disso, a utilidade relacionada ao bemestar individual seja representada pela renda, felicidade ou pela satisfação de desejos não fornece uma base informacional satisfatória. Por outro lado, embora a abordagem dos bens primários de Rawls seja um avanço em relação à abordagem das utilidades, ainda assim ela também não resolve o problema, uma vez que julga as oportunidades que as pessoas têm pelos meios que elas possuem e acaba não levando em conta as amplas variações que elas apresentam quanto às capacidades de converter os bens primários em bem viver.

Ao analisar a questão da pobreza, com base nas análises realizadas por Sen, é possível concluir que o primeiro requisito para se chegar a um conceito de pobreza é ter um critério sobre a quem deveria ser direcionado o foco de análise e que o problema de avaliação da pobreza, assim como da desigualdade, depende do espaço de informação utilizado.

Quanto ao problema de pesquisa, com base na análise bibliográfica restou confirmada a hipótese de que tanto em relação à questão do bem-estar quanto

\footnotetext{
8 Neste ponto Sen faz uma crítica à conceituação de pobreza apresentada por Rein (1971) no qual “às pessoas não deveria ser permitido se tornarem tão pobres que ofendessem ou se tornassem prejudiciais à sociedade. Não é tanto a miséria e o sofrimento dos pobres, mas o desconforto e o custo para a comunidade que é crucial para esta visão da pobreza. Temos um problema de pobreza, na medida em que a baixa renda cria problemas para aqueles que não são pobres".
} 
da pobreza a abordagem dos funcionamentos e capacitações possibilita uma resposta mais consistente do ponto de vista da abrangência da diversidade de nuances das características individuais dos seres humanos do que a abordagem utilitarista e dos bens primários de Rawls.

\section{Referências}

Harsanyi, J. C. (1955). "Cardinal welfare, individualistic ethics, and interpersonal comparisons of utility". Journal of Political Economy volume (63): 309-321.

Hausman, D; Mcpherson, M. (2006). Economic Analysis, Moral Philosophy and Public Policy. New York: Cambridge University Press.

Pindyck, R.S.; Rubinfeld, D.L. (2002). Microeconomia. São Paulo: Prentice Hall.

Rawls, J. (2008). Uma teoria da justiça. São Paulo: Martins Fontes.

Rein, M. (1971). Problems in the definition and measurement of poverty. London: Heineman.

Sen; A (1976). "Poverty: An Ordinal Approach to Measurement". Econometrica Volume (44): $219-231$.

Sen, A. (1979). Equality of what? The tanner Lectures on Human Values. Stanford: Stanford University.

Sen, A. (1981). Poverty and Famines. An essay an entitlement and deprivation. Oxford: Claredon Press.

Sen, A; WILLIAMS, B. (1983). Utilitarianism and beyond. London: Cambridge University Press.

Sen, A. (1985). Well-Being, agency and Freedom: The Journal of Philosophy volume (82):169-221.

Sen, A. (1999). Sobre ética e economia. São Paulo: Companhia das Letras.

Sen, A. (2001). Desenvolvimento como Liberdade. São Paulo: Companhia das letras.

Sen, A. (2009). The Idea of Justice. Cambridge: Harvard University Press.

Varian, H. (2006). Microeconomia. Princípios Básicos. São Paulo: Campus. 